\title{
A simulation model of the three-dimensional architecture of the maize root system
}

\author{
L. PAGÈS ${ }^{1}$, M. O. JORDAN ${ }^{1}$ and D. PICARD ${ }^{2}$ \\ 'INRA, Station d'Agronomie, Domaine $S^{t}$-Paul, F-84140 Montfavet, France and ${ }^{2} I N R A$, Département \\ d'Agronomie, F-78850 Thiverval-Grignon, France
}

Received 15 September 1988. Revised April 1989

Key words: architecture, maize, mathematical model, root growth, root development, simulation model, spatial distribution, Zea mays

\begin{abstract}
In order to study the nutrient and water uptake of roots in situ, we need a quantitative three-dimensional dynamic model of the root system architecture.

The present model takes into account current observations on the morphogenesis of the maize root system. It describes the root system as a set of root axes, characterised by their orders and their inter-node of origin. The evolution of the simulated pattern is achieved by three processes, occuring at each time step: emission of new primary root axes from the shoot, growth and branching of existing root axes. The elongation of an axis depends on its order, inter-node and local growing conditions. Branches appear acropetally at a specified distance from the apex and from former branches, along ranks facing xylem poles, with a branching angle specific to their order and inter-node.

From the three-dimensional branched patterns simulated by the model, various outputs, such as root profiles or cross-section maps can be computed, compared to observed data and used as inputs in uptake models. A number of examples of such possible outputs are presented.
\end{abstract}

\section{Introduction}

The amounts of water and mineral nutrients available for plant growth and production are limited in the soil. Furthermore, these nutrients have a heterogeneous distribution, and show differences in mobility. In such an environment, the spatial distribution and the dynamics of the root system will affect the overall level of absorption.

It is therefore important to describe the spatial distribution of roots over time in order to create models for the soil-plant system.

Root systems are usually described by root profiles (Gerwitz and Page, 1974). These profiles, however, do not take into account the heterogeneous horizontal distribution of roots. Bi-dimensional root maps (Tardieu and Manichon, 1986) give a better description of such heterogeneities, but they remain static and give limited information concerning the full three-dimensional geometry.

The absorption efficiency of roots may depend on morphological and structural characteristics such as age or diameter. The absorption efficiency of the root system as a whole depends on the structure of its network (Fitter, 1987). None of these structural characteristics can be found in root maps, as these merely describe the location of the roots.

Other descriptions take into account the connections between roots and the structure of the root network. Some qualitative classifications based on root systems form and structure have been established (Cannon, 1949; Weaver, 1958). Kahn (1977), working on tropical trees, Klepper et al. 
(1984) and Picard et al. (1985) working on cereals, gave a more dynamic view of the root system structure by observing morphogenesis in situ.

Quantitative simulation models of growth and development can be derived from such observations (Diggle, 1988; Lungley, 1973; Pagès and Aries, 1988; Porter et al., 1986; Rose, 1983).

Thus, we have used in situ observations of the morphogenesis of the maize root system (Jordan, 1986; Picard et al., 1985) to create an architectural simulation model. We have attempted to put together previously unrelated elements of information. The main characteristics of the morphogenesis of the maize root network were translated into a mathematical model, and quantified by parameters. This model allows the generation of three-dimensional branching patterns over time. Model outputs may include spatial and structural information such as age, diameter, and connections between roots. A number of model outputs will be presented in this paper along with a discussion of various ways for calibrating and validating the model with experimental data.

\section{Principles of the model}

\section{General properties}

A root system may be considered as a set of axes, which are each derived from a meristem and characterised by a ramification order: first-order axes (or primary axes) are directly connected to the stem; second-order axes (or secondary axes) are connected to first-order axes; and so forth.

Time is divided into equal time steps. The duration of the simulated period and the length of the time step are specified by the user. At each time step, new primary axes may appear, and each axis of the existing root systems grows and may branch.

The simulated three-dimensional structure is continuously stored in a record file consisting of 'root segments'. Each root segment represents the growth of axis that was generated during each elementary time step. Record fields contain all the information required for simulation and output computation: three-dimensional coordinates, connections, date of recording, ramification order, etc... This file is updated at each time step.

\section{Primary root emission}

A maize plant consists of elementary units, called phytomeres, which are stacked together. The phytomeres of the stem base have short inter-nodes that give rise to primary roots (Girardin et al., 1986). From the base to the top of the stem, successive inter-nodes can be numbered from 0 to $N$ (the inter-node that gives rise to seminal roots in numbered 0 ). The roots are emitted successively from the base to the top, and the emission on a given inter-node only begins after the emission on the previous inter-node is completed.

Picard et al. (1985) showed that primary roots are steadily emitted until flowering, and gave for the 'Dea' variety the following linear relationship between the total number of visible leaves and the rank of the inter-node where emission occurs:

$$
I_{\mathrm{R}}=0.265+0.495 \mathrm{~L}
$$

( $I_{\mathrm{R}}$ is the inter-node rank, and $L$ is the number of leaves).

The number of primary roots can also be related to the sum of air temperatures since the date of seeding (Figure 1, after Jordan, 1986):

$$
R=0.0394 S
$$

( $R$ is the number of roots, and $S$ the sum of tem-

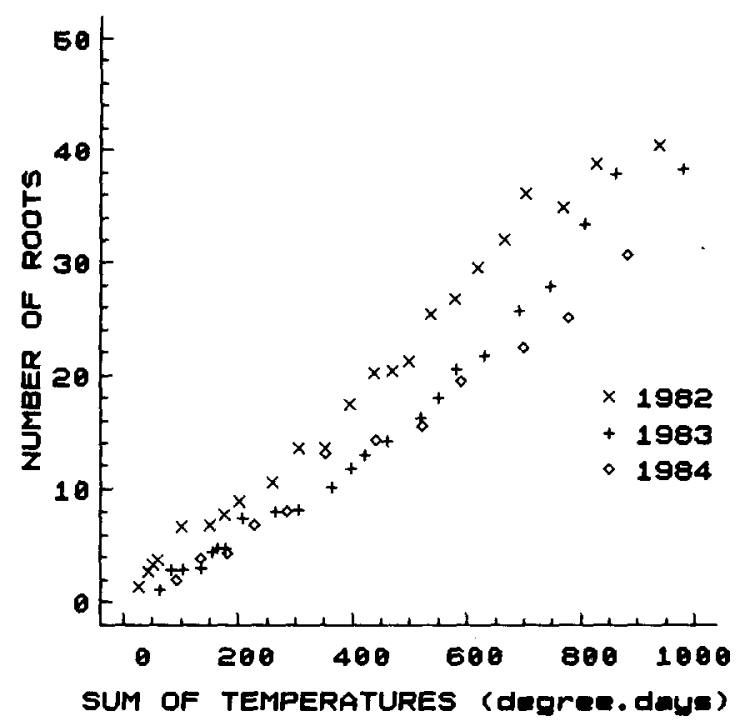

Fig. 1. Relationship between the total number of primary roots and the sum of temperatures above $6^{\circ} \mathrm{C}$ for the variety 'Dea' in the field (after Jordan, 1986). 
peratures, with $6^{\circ} \mathrm{C}$ as zero-growth temperature).

In the present model, users may choose either observed relationship. The former relationship may be more attractive as it remains the same from one year to another. However, its use in the present model requires the introduction of the phyllochrone time scale.

Picard et al. (1985) have also studied the distributions of the numbers of primary roots on each inter-node. They have shown that the distributions differ according to the inter-node rank. They could not find evidence of correlations between the numbers of primary roots on two successive internodes. Therefore, we have used as model parameters the mean numbers of primary roots observed at each inter-node. They also showed that the distribution variance increased with the internode rank. Thus, the numbers of primary roots could be drawn from probability distributions of increasing variances.

In order to define coordinates of the starting points of primary roots, it is essential to know the shape and position of the plant base. The seed was assumed to be at a given and constant depth and to give rise to a vertical mesocotyl. The stem base was assumed to be cone-shaped. Figure 2 illustrates the kind of geometry we used. Users can modify geometrical quantitative characteristics (programme constants).

Primary root orientation is defined by two angles: a vertical angle $\left(\theta_{\mathrm{v}}\right)$ relatively to the vertical direction, and a horizontal angle $\left(\theta_{\mathrm{h}}\right)$ relatively to a reference direction in the horizontal plane. This horizontal angle $\left(\theta_{\mathrm{h}}\right)$ is computed from the number of roots on each inter-node, assuming that the roots are uniformly distributed around the vertical axis. The direction of the first root is chosen at random.

Primary root emission is exhaustively defined in space and time by these hypotheses and these parameters.

\section{Root growth}

The length and direction of each growing axis must be evaluated in order to generate a threedimensional structure.

The program function that computes axis elongation processes the following inputs: axis

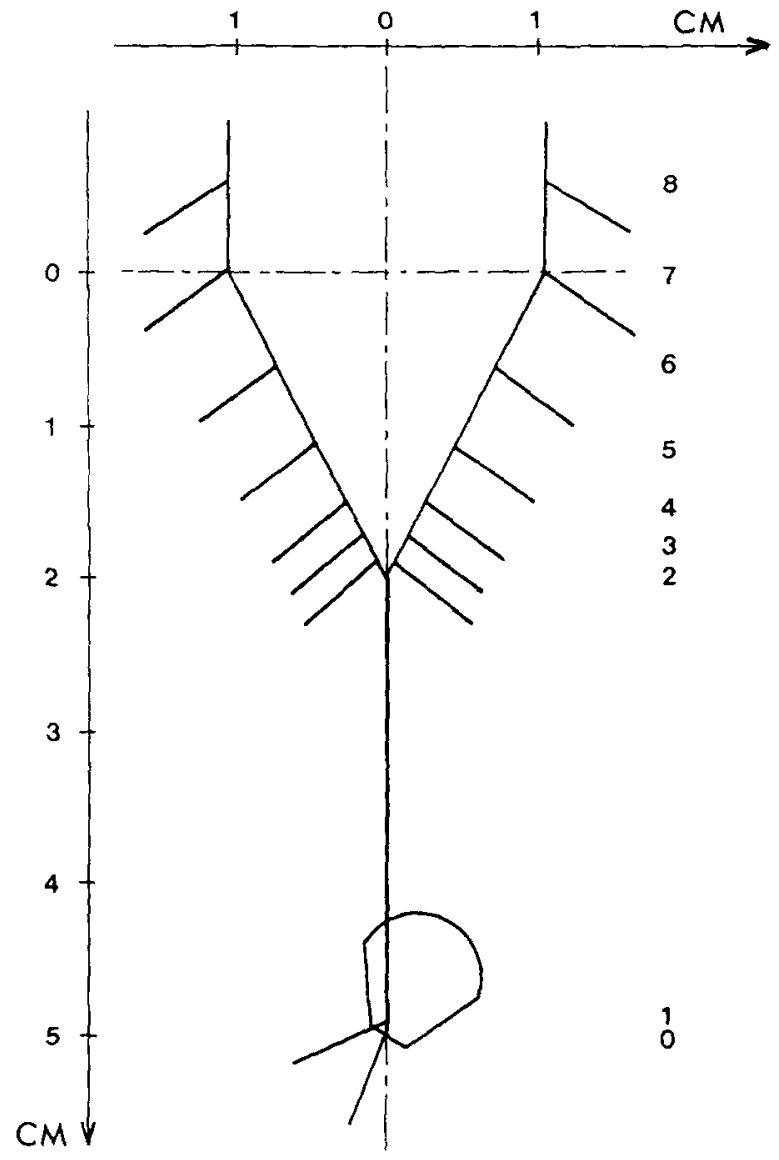

Fig. 2. Position and shape of the stem base, as used in the present simulations.

order, inter-node rank, age, location $(x, y, z)$ of the axis apex. Consequently, this function can express any sub-model that describes axis growth according to its structural characteristics (inter-node, order, age) and to the physico-chemical properties of the soil (temperature, mechanical impedance), which must be mapped by the user beforehand.

The growth direction $(D)$ is computed from three directional components (Figure 3), represented by mathematical vectors, which are added:

- the initial direction $\left(D_{-1}\right)$ of the root at the previous time step: this vector length is equal to 1 .

- a vertical vector representing geotropism whose length is proportional to both the elongation during the time step under study and a parameter called $G$, defined according to the location, the order and the inter-node.

- a vector representing mechanical constraints, whose length is proportional to both the elongation 


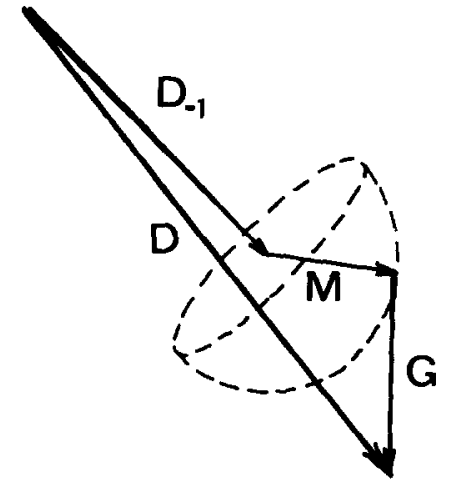

Fig. 3. Growth direction as computed in the model. $D_{-1}$ : initial direction, $M$ : mechanical constraint, $G$ : geotropism, $D$ : resulting growth direction.

during the time step under study and a parameter $M$, defined according to the location, the order and the inter-node. Mechanical constraints may be considered as isotropic (random vector) in some parts of the environment, whereas in other parts they may be pointing in a given direction and then may be represented by a fixed vector.

Similarly, other tropisms could be integrated into the model.

\section{Root branching}

Branch position on the carrier axis (Figure 4). Our hypotheses concerning the localisation of lateral roots were adapted from Lungley (1973), and checked experimentally by Jordan (1986).

As under normal circumstances lateral roots arise at some distance from the axis base, we define the following parameter: "length of the basal nonbranched zone' $\left(L_{B}\right)$. Similarly, as lateral roots cannot be found close to the root apex, we define the following parameter: "length of the apical nonbranching zone' $\left(L_{A}\right)$. In the present model, no branching occurs until the root has become longer than the sum of $L_{B}$ and $L_{A}$. After this threshold has been reached, lateral roots appear at regular intervals. Another parameter is thus introduced: 'interbranch distance' (I). The expansion of the branched zone follows the growth of the axis in a strictly acropetal way.

Branching orientation (Figure 5). A branch base must also be given a specific direction. The branch-
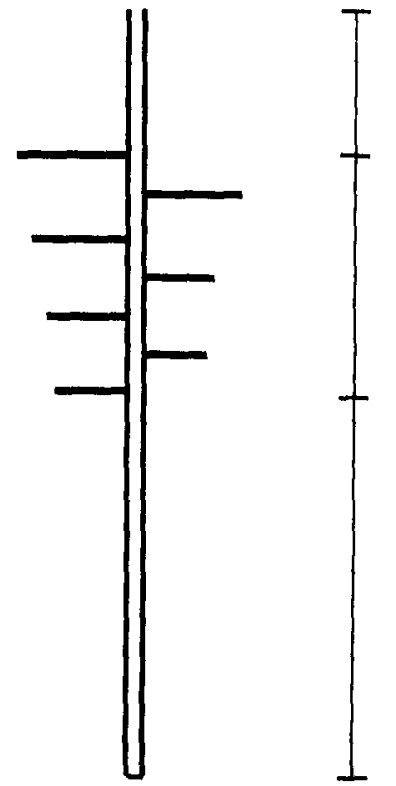

BASAL

NON-BRANCHED

ZONE

BRANCHED

ZONE

APICAL

NON-BRANCHING

ZONE

Fig. 4. Position of branches along the root axis.

ing orientation was characterised by two angles: the insertion angle $\left(\phi_{1}\right)$, and the radial angle $\left(\phi_{R}\right)$.

The insertion angle was defined as the angle between the mother root and its branch, in the plane of these two axes. Users have to specify this angle.

The radial angle was defined as the angle between a given direction and the branch direction, in the plane perpendicular to the mother root. According to Bell and McCully (1970), lateral roots are initiated in some pricycle cells that are facing xylem poles. As the present model supposes xylem poles to be regularly spaced around the axis, it is possible to obtain the potential branching orientations from the total number of xylem poles (which will be referred to as $X$ ). The radial angle is therefore obtained by the following formula:

$$
\varnothing_{R}=2 \pi N / X
$$

(where $N$ is a random integer between 1 and $X$ ).

\section{Outputs}

\section{Introduction}

It must be emphasized that parameter estimation and model validation are obviously hampered by 

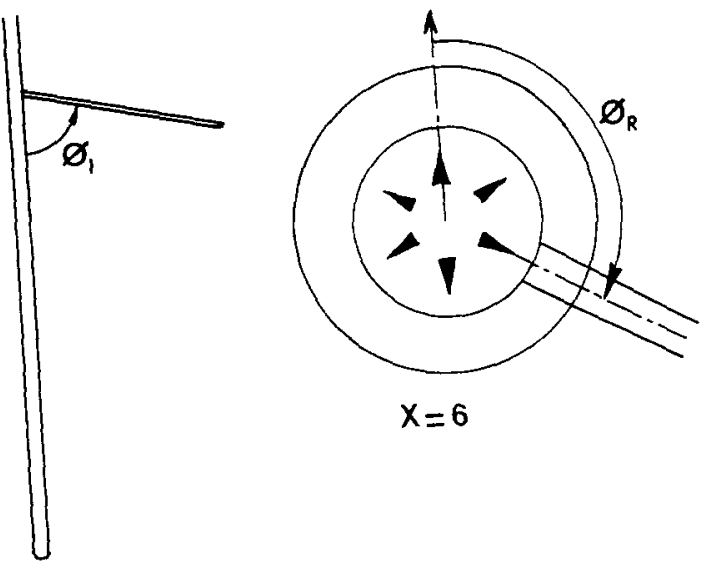

Fig. 5. Branch orientation, $\phi_{j}$ : insertion angle, $\phi_{R}$ : radial angle, $X$ : number of xylem poles.

Table 1. General parameters used in the present simulations

\begin{tabular}{|c|c|}
\hline $\begin{array}{l}\text { Inter-node rank where } \\
\text { emission occurs }\end{array}$ & $\begin{array}{l}I_{R}=\text { integer }(0.265+0.495 L) \\
L_{:} \text {number of leaves, } I_{R} ; \text { inter-node rank }\end{array}$ \\
\hline $\begin{array}{l}\text { Growth rate of primary } \\
\text { roots }(\mathrm{cm} / \text { day })\end{array}$ & $\begin{array}{l}\text { constant } \\
2.0\end{array}$ \\
\hline $\begin{array}{l}\text { Growth rate of secondary } \\
\text { roots }(\mathrm{cm} / \text { day) }\end{array}$ & $\begin{array}{l}6.4 \mathrm{e}^{-0.8 T} \\
T: \text { age of the root meristem (days) }\end{array}$ \\
\hline $\begin{array}{l}\text { Growth rate of tertiary } \\
\text { roots }(\mathrm{cm} / \text { day })\end{array}$ & $\begin{array}{l}1.5 \mathrm{e}^{-0.8 T} \\
T: \text { age of the root meristem (days) }\end{array}$ \\
\hline Mechanical constraint & $\begin{array}{l}\text { isotropic in the ploughed layer }(25 \mathrm{~cm}): 0.02 \\
\text { Vertical under the ploughed layer: } 0.08\end{array}$ \\
\hline
\end{tabular}

the difficulties encountered in observing and measuring root systems (Böhm, 1979). A number of parameters, such as those concerning the number and rate at which primary roots emerge, can be measured in situ (Picard et al., 1985). Other parameters such as growth rates must be estimated from root profiles or root maps.

In the present section, we shall give a few sample outputs from our model in order to underline its value and its potential for estimation and validation with the kind of data that are classically obtained. The following outputs were computed from simulated structures by specific and independent programs. The hypotheses and parameters used for all the simulations are presented in Tables 1 and 2 .

\section{Visual outputs}

It is very difficult, if not impossible to observe a whole root system grown in the field, with its full spatial structure. However, some attempts have been made to give representations of maize root systems, for instance diagrams drawn after partial excavation (Cannon, 1949; Kutschera, 1960) or photographs taken after excavation with a pinboard (Jordan, 1986).

Table 2. Other parameters used in the present simulations: parameters depending on inter-node number and/or ramification order

\begin{tabular}{|c|c|c|c|c|c|c|c|c|c|c|}
\hline \multirow[t]{2}{*}{ Parameter } & \multirow[t]{2}{*}{ Order } & \multicolumn{9}{|c|}{ Inter-node number } \\
\hline & & 0 & 1 & 2 & 3 & 4 & 5 & 6 & 7 & 8 \\
\hline Number of primary roots & & 1 & 3 & 3 & 2 & 3 & 3 & 4 & 9 & 12 \\
\hline Insertion angle (rad) & $\begin{array}{l}1 \\
2 \\
3\end{array}$ & $\begin{array}{l}0.0 \\
1.1 \\
1.1\end{array}$ & $\begin{array}{l}1.1 \\
1.1 \\
1.1\end{array}$ & $\begin{array}{l}1.1 \\
1.1 \\
1.1\end{array}$ & $\begin{array}{l}1.1 \\
1.1 \\
1.1\end{array}$ & $\begin{array}{l}1.1 \\
1.1 \\
1.1\end{array}$ & $\begin{array}{l}1.1 \\
1.1 \\
1.1\end{array}$ & $\begin{array}{l}1.1 \\
1.1 \\
1.1\end{array}$ & $\begin{array}{l}1.1 \\
1.1 \\
1.1\end{array}$ & $\begin{array}{l}1.1 \\
1.1 \\
1.1\end{array}$ \\
\hline Number of xylem poles & $\begin{array}{l}1 \\
2 \\
3\end{array}$ & $\begin{array}{l}9 \\
5 \\
-\end{array}$ & $\begin{array}{l}9 \\
5 \\
-\end{array}$ & $\begin{array}{l}9 \\
5 \\
-\end{array}$ & $\begin{array}{l}9 \\
5 \\
-\end{array}$ & $\begin{array}{l}9 \\
5 \\
-\end{array}$ & $\begin{array}{l}9 \\
5 \\
-\end{array}$ & $\begin{array}{l}9 \\
5 \\
-\end{array}$ & $\begin{array}{l}9 \\
5 \\
-\end{array}$ & $\begin{array}{l}9 \\
5 \\
-\end{array}$ \\
\hline Geotropism & $\begin{array}{l}1 \\
2 \\
3\end{array}$ & $\begin{array}{l}0.004 \\
0.05 \\
0\end{array}$ & $\begin{array}{l}0.005 \\
0.05 \\
0\end{array}$ & $\begin{array}{l}0.005 \\
0.05 \\
0\end{array}$ & $\begin{array}{l}0.009 \\
0.05 \\
0\end{array}$ & $\begin{array}{l}0.03 \\
0.05 \\
0\end{array}$ & $\begin{array}{l}0.07 \\
0.05 \\
0\end{array}$ & $\begin{array}{l}0.1 \\
0.05 \\
0\end{array}$ & $\begin{array}{c}0.12 \\
0.05 \\
0\end{array}$ & $\begin{array}{l}0.14 \\
0.05 \\
0\end{array}$ \\
\hline $\begin{array}{l}\text { Length of apical } \\
\text { non-branching zone }(\mathrm{cm})\end{array}$ & $\begin{array}{l}1 \\
2 \\
3\end{array}$ & $\begin{array}{r}15 \\
2 \\
-\end{array}$ & $\begin{array}{r}15 \\
2 \\
-\end{array}$ & $\begin{array}{r}15 \\
2 \\
-\end{array}$ & $\begin{array}{r}15 \\
2 \\
-\end{array}$ & $\begin{array}{r}15 \\
2 \\
-\end{array}$ & $\begin{array}{r}15 \\
2 \\
-\end{array}$ & $\begin{array}{r}15 \\
2 \\
-\end{array}$ & $\begin{array}{r}15 \\
2 \\
-\end{array}$ & $\begin{array}{r}15 \\
2 \\
-\end{array}$ \\
\hline $\begin{array}{l}\text { Length of the basal } \\
\text { non-branched zone }(\mathrm{cm})\end{array}$ & $\begin{array}{l}1 \\
2 \\
3\end{array}$ & $\begin{array}{l}0.7 \\
0.7 \\
-\end{array}$ & $\begin{array}{l}0.7 \\
0.7 \\
-\end{array}$ & $\begin{array}{l}0.7 \\
0.7 \\
-\end{array}$ & $\begin{array}{l}0.7 \\
0.7 \\
-\end{array}$ & $\begin{array}{l}0.7 \\
0.7 \\
-\end{array}$ & $\begin{array}{l}0.7 \\
0.7 \\
-\end{array}$ & $\begin{array}{l}0.7 \\
0.7 \\
-\end{array}$ & $\begin{array}{l}0.7 \\
0.7 \\
-\end{array}$ & $\begin{array}{l}0.7 \\
0.7 \\
-\end{array}$ \\
\hline $\begin{array}{l}\text { Inter-branch } \\
\text { distance }(\mathrm{cm})\end{array}$ & $\begin{array}{l}1 \\
2 \\
3\end{array}$ & $\begin{array}{l}0.7 \\
0.7 \\
-\end{array}$ & $\begin{array}{l}0.7 \\
0.7 \\
-\end{array}$ & $\begin{array}{l}0.7 \\
0.7 \\
-\end{array}$ & $\begin{array}{l}0.7 \\
0.7 \\
-\end{array}$ & $\begin{array}{l}0.7 \\
0.7 \\
-\end{array}$ & $\begin{array}{l}0.7 \\
0.7 \\
-\end{array}$ & $\begin{array}{l}0.7 \\
0.7 \\
-\end{array}$ & $\begin{array}{l}0.7 \\
0.7 \\
-\end{array}$ & $\begin{array}{l}0.7 \\
0.7 \\
-\end{array}$ \\
\hline
\end{tabular}




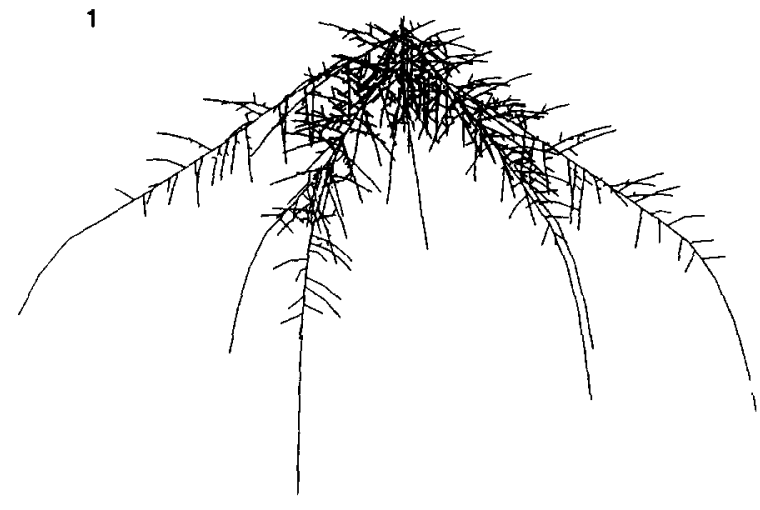

2

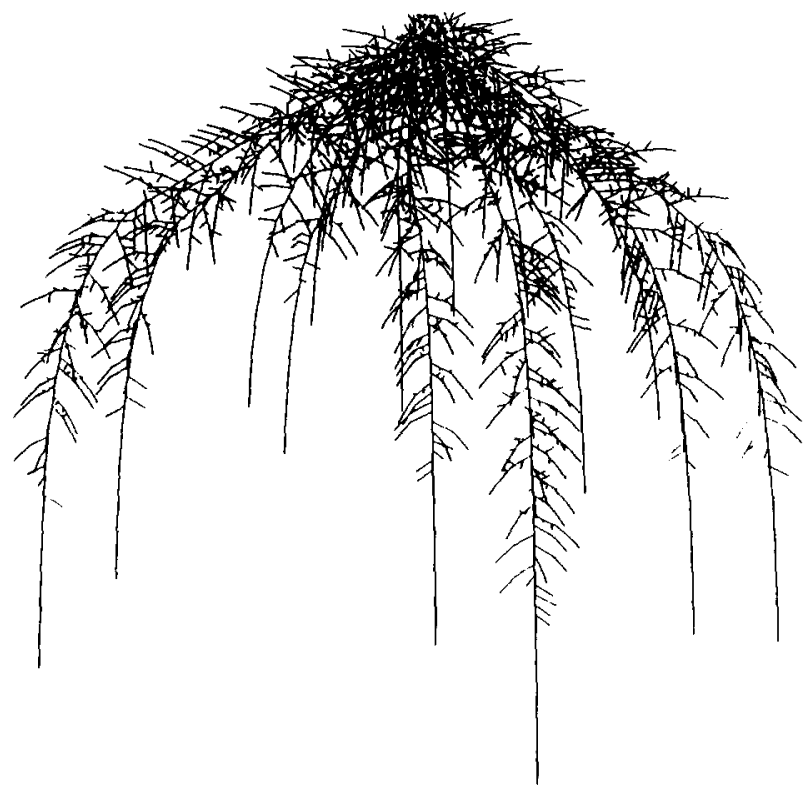

Fig. 6. Projections of three-dimensional structures. The parameters given in Tables 1 and 2 were used. 1: after 40 days (10 leaves), 2: after 60 days ( 14 leaves).

Figure 6 shows two different simulated patterns. The program used for these pictures is interactive and allows users to rotate the three-dimensional structures by computing any orthogonal projection.

\section{Root profiles}

Many root density profiles (i.e. vertical distributions of mean root density) can be found in the literature (Gerwitz and Page, 1974) because they are straightforward representations of data obtained from soil cores. Root density is generally expressed as length, mass or number of root apices, relatively to soil volume or soil surface.

It is obviously possible to compute such root profiles from the simulated patterns. Figure 7 shows some examples of simulated root length profiles in the same plant at various stages. The present model can be used to study to what extent profile characteristics are sensitive to parameter variations.

This one-dimensional description of the root system can serve as input in absorption models only if root density is assumed to be homogeneous in the horizontal plane. This hypothesis is valid only if the soil is horizontally homogeneous, and if the crop has roots growing uniformly in the underground strata. Note that in the present model coefficients of variation of the horizontal root density may be computed using various hypotheses in order to assess whether the assumption of homogeneity is acceptable.

\section{Root maps}

One-dimensional root profiles are of little value in cases where the above assumption of root density homogeneity is not valid. Plant isolation at the early stages of the crop, or soil structure heteroge-

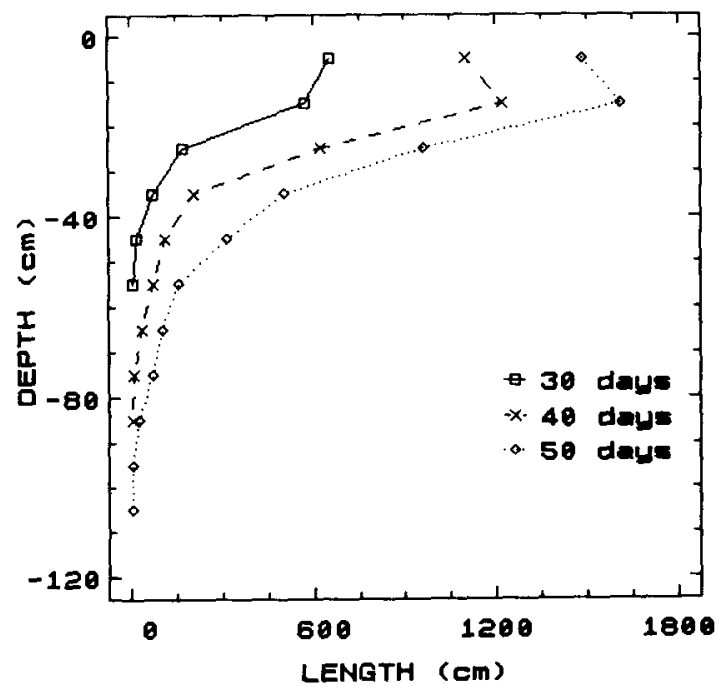

Fig. 7. Theoretical root length profiles. The parameters given in Tables 1 and 2 were used. $\square-\square$ : after 30 days ( 7 leaves), $x-x$ : after 40 days ( 10 leaves), $\diamond \diamond$ : after 50 days (12 leaves). 

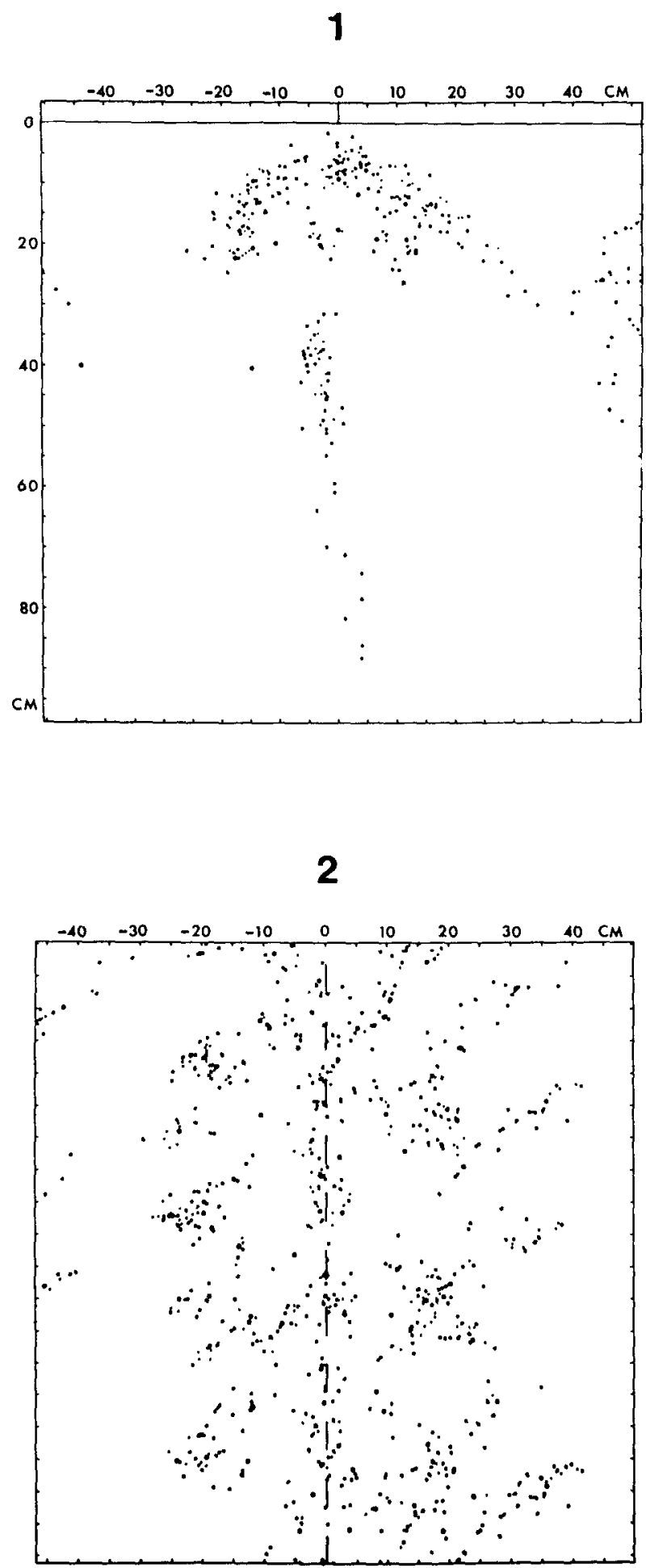

Fig. 8. Cross sections of a set of 50 days old (12 leaves) simulated patterns localised in space like in a crop (see the text). Each graduation represents $5 \mathrm{~cm}$. The dashed lines represent the row of the crop. 1: vertical plane perpendicular to the row, midway between two plants, 2 : horizontal plane, $20 \mathrm{~cm}$ deep. neity can result in root heterogeneity (Tardieu and Manichon, 1986). In their study on maize, these authors showed that the horizontal density of roots varied according to the compaction of the ploughed layers of the soil.

In such situations, it becomes necessary to describe spatial root distribution with more detail. Models may then be validated using root maps obtained from trench walls, whether horizontal or vertical (Böhm, 1979).

The present software includes a program that computes cross sections of the simulated structures, thus yielding theoretical root maps that can be tested against experimental data. On Figure 8, such theoretical root maps are presented. To compute them, a set of 17 structures have been simulated, and these structures were positioned in space as they are in classical crops. On the row, the distance between two plants is $15 \mathrm{~cm}$, and the distance between two rows is $80 \mathrm{~cm}$.

The comparison between theoretical and observed root maps involves using adequate statistical tools to assess morphological differences that affect physiological functioning.

\section{Discussion and conclusion}

The present model, with the associated software, is mainly a tool for analysis and synthesis on root system growth, development, and spatial distribution. It allows hypotheses to be formulated and then tested using the outputs they yield. It can also be used to plan experiments and measurements, as it helps to underline the parameters that must be studied in detail. This model is also a powerful tool to optimize in situ sampling, whenever soil cores are taken or endoscopic tubes are inserted.

This work can be compared with that done by Diggle (1988), who also simulated three-dimensional structure of fibrous root systems. However, the present model takes into account the specifity of primary root emission on maize kinetically (Picard et al., 1985) as well as geometrically (Jordan, 1986). In order to characterise the emergence and location of branches on the mother root, we used only spatial parameters (length or distance), like Lungley (1973), as opposed to Porter et al. (1986) or Diggle (1988) who combined space and duration parameters. We made this choice because we 
thought geometrical parameters are easier to obtain in situ, merely by sampling and direct measurement. Our description of growth direction includes the case where mechanical constraints are anisotropic, as occurs in many fields under the ploughed layer, for instance because of vertical channels made by earthworms (Wang et al., 1986).

The program corresponding to this model is written in such a way that users can integrate their own sub-models in order to test their own hypotheses. Thus, users can vary the growth rates of axes according to their structural position (inter-node, ramification order), and to their spatial position, which takes into account the spatial and temporal variability of soil properties (mechanical impedance, temperature). Users have just to specify the sub-model to be used in the elongation-computing sub-program.

The duration of the simulated period is not limited by memory constraints because each pattern, as it is generated, is recorded in a computer disk file that is updated at each time step. The complete storage of patterns allows the association of several plants in a crop (assuming that parameters have been estimated in the crop), and the calculation of various outputs corresponding to field observations: root maps, soil core samples, minirhizotron pictures, etc.

In order to complete such a model, it would now be important to take into account the carbohydrate distribution among the root system and the whole plant. In this way, it will be possible to modulate growth according to the quantity of photosynthetic assimilates, and to consider the growth correlations within the root system, which may be essential when the soil is very heterogeneous (Brouwer, 1981).

\section{References}

Bell J K and McCully M E 1970 A histological study of lateral root initiation and development in Zea mays. Protoplasma 70, 179-205.

Böhm W 1979 Methods of studying root systems. In Ecological Studies. Springer-Verlag, Berlin. $188 \mathrm{p}$.

Brouwer R 1981 Co-ordination of growth phenomena within a root system of intact maize plants. Plant and Soil 63, 65-72.
Cannon W A 1949 A tentative classification of root systems. Ecology 30, 542-548.

Diggle A J 1988 ROOTMAP: A model in three-dimensional coordinates of the growth and structure of fibrous root systems. Plant and Soil 105, 169-178.

Fitter A H 1987 An architectural approach to the comparative ecology of plant root systems. New Phytol. 106, 61-77.

Gerwitz A and Page E R 1974 An empirical mathematical model to describe plant root systems. J. Appl. Ecol. 11, 773 781 .

Girardin P, Jordan M O, Picard D and Trendel R 1986 Harmonisation des notations concernant la description morphologique d'un pied de mais (Zea mays L.). Agronomie 6 , 873-875.

Jordan M O 1986 Mise en place du système racinaire du maïs. Définition et caractérisation au champ et en conditions contrôlées des paramètres descriptifs de la structure racinaire. Construction de l'organigramme d'un modèle cinétique. Thèse de l'Université Louis Pasteur de Strasbourg.

Kahn F 1977 Analyse structurale des systèmes racinaires des plantes ligneuses de la forêt tropicale dense humide. Candollea 32, 321-358.

Klepper B, Belford R K and Rickman R W 1984 Root and shoot development in winter wheat. Agron. J. 76, 117-122.

Kutschera L 1960 Wurzelatlas mitteleuropäischer Ackerunkräuter und Kulturpflanzen. DLG-Verlags-GmbH, Frankfurt am Main. $574 \mathrm{p}$.

Lungley D R 1973 The growth of root systems: A numerical computer simulation model. Plant and Soil 38, 145-159.

Pagès L and Aries F 1988 SARAH: modèle de simulation de la croissance, du développement, et de l'architecture des systèmes racinaires. Agronomie 8, 889-896.

Picard D, Jordan M O and Trendel R 1985 Rythme d'apparition des racines primaires du mais (Zea mays $\mathrm{L}$.). 1. Etude détaillée pour une variété en un lieu donné. Agronomie 5, 667-676.

Porter J R, Klepper B and Belford R K 1986 A model (WHTROOT) which synchronizes root growth and development with shoot development for winter wheat. Plant and Soil 92, 133-145.

Rose D A 1983 The description of the growth of root systems. Plant and Soil 75, 405-415.

Tardieu F and Manichon H 1986 Caractérisation en tant que capteur d'eau de l'enracinement du maïs en parcelle cultivée. 2. Une méthode d'étude de la répartition verticale et horizontale des racines. Agronomie 6, 415-425.

Wang J, Hesketh J D and Woolley J T 1986 Preexisting channels and soybean rooting patterns. Soil Sci. 141, 432-437.

Weaver J E 1958 Classification of root systems of forbs of grassland and a consideration of their significance. Ecology $39,393-401$

Copies of the original program, written in Turbo-Pascal (Borland International) and running on any compatible IBM PC computer, are available on request (please provide a 5.25 inch blank diskette). 